6 Medical Research Council Working Party. MRC trial of treatment of mild hypertension: principal results. Br Med f 1985;291:97-104.

Cruikshank JM, Thorp JM, Zacharias FJ. Benefits and potential harm of lowering high blood pressure. Lancet 1987; $581-4$.

8 Pickering TG, Harshfield GA, Kleinert HD, Blank S, Laragh JH. Blood pressure during normal daily activities, sleep, and exercise. Comparison of values in normal and hypertensive subjects. IAMA 1982;247:992-6.

9 Janeway TC. The clinical study of blood pressure. A guide to the use of the sphygmomanometer. New York: D Appleton, 1904:120.

10 Smirk FH. Casual and basal blood pressures. IV. Their relationship to the supplemental pressure with a note on statistical implications. Br Heart $\mathcal{F}$ 1944;6:176-82.

11 O'Brien E, Fitzgerald D, O'Malley K. Blood pressure measurement: current practice and future trends. Br Med f 1985;290:729-34.

2 Waeber B, Scherrer U, Petrillo A, et al. Are some hypertensive patients overtreated? A prospective study of ambulatory blood pressure recording. Lancet 1987;ii:732-4.

13 Fitzgerald D, O'Callaghan W, O'Brien E, Johnson H, Mulcahy R, Hickey N. Home recording of blood pressure in the management of hypertension. Ir Med f 1985;78:216-8.
14 Julius S, Ellis CN, Pascual AV, et al. Home blood pressure determination. Value in borderline ("labile") hypertension. ҰAMA 1974;229:663-6.

15 O'Brien E, O'Malley K. ABC of blood pressure measurement: technique. Br Med $\mathcal{f}$ 1979; ii:982-4.

16 Flapan AD, Stewart SE, McDougal F, Padfield PL. Is self home-monitoring of blood pressure as good as 24-hour ambulatory monitoring? I Hypertens [Suppl] 1987;5:491-3.

17 Kenny RA, Brennan M, O'Malley K, O'Brien E. Blood pressure measurements in borderline hypertension. $\mathcal{F}$ Hypertens [Suppl] 1987;5:483-5.

18 Perloff $\mathrm{D}$, Sokolow $\mathrm{M}$, Cowan $\mathrm{R}$. The prognostic value of ambulatory blood pressure. JAMA 1983;249:2792-8

19 Devereux RB, Pickering TG, Harshfield GA, et al. Left ventricular hypertrophy in patients with hypertension: importance of blood pressure response to regularly recurring stress. Circulation 1983;68:470-6.

20 Pickering TG, Devereux RB. Ambulatory monitoring of blood pressure as a predictor of cardiovascular risk. Am Heart f 1987;114:925-8.

21 Pickering TG, James GD, Boddie C, Harshfield GA, Blank S, Laragh JH. How common is white coat hypertension? JAMA 1988;259:225-8.

\title{
Overtreating hypertension
}

\section{Mortality from coronary artery disease may be increased if pressures are dropped too low}

Doctors have long been anxious that they may do more harm than good when treating mild hypertension. Rapid reductions of blood pressure may precipitate stroke, myocardial infarction, or a deterioration in renal function ${ }^{1-3}$; this has led to the disappearance of parenteral antihypertensive drugs except for use in patients with hypertensive encephalopathy. Some have worried that over enthusiastic treatment in elderly hypertensive patients with oral drugs might also precipitate cerebral underperfusion, ${ }^{45}$ and in 1979 an alarming increase in the relative risk of coronary heart disease was reported in hypertensive patients whose diastolic pressures were reduced to below $90 \mathrm{~mm} \mathrm{Hg} .{ }^{6}$ This paper was largely ignored.

Now the topic of the relation between blood pressure reduction and the complications of hypertension has been reactivated. Traditionally doctors have tried to lower blood pressure to as near as possible to normal, but in March 1987 Cruickshank et al argued that the relation between mortality from coronary artery disease and the blood pressure achieved after treatment was J shaped - in other words, lowering the blood pressure too far caused extra deaths. ${ }^{7}$ In this issue (p 1227) Cruickshank suggests that excess deaths occur in patients with narrowing coronary arteries. In patients with no evidence of coronary heart disease the relation between mortality and the blood pressure achieved is not $\mathrm{J}$ shaped.

Other groups have also reported a $\mathrm{J}$ shaped curve,$^{8-10}$ and both the Glasgow Blood Pressure Clinic ${ }^{9}$ and the Department of Health and Social Security Hypertension Care Computing Group ${ }^{10}$ have observed it in patients with or without coronary ischaemia at presentation. This increased mortality was observed with diastolic pressures after treatment ranging from $80 \mathrm{~mm} \mathrm{Hg}$ to $90 \mathrm{~mm} \mathrm{Hg}$. It is not therefore resulting from extreme blood pressure reduction. The main problem with all these retrospective studies is that the quality of the data is often poor, relying on passing, often uninterested, junior doctors. Also despite the large size of the clinics the numbers of patients with coronary heart disease who require antihypertensive treatment and who achieve "excellent" control of blood pressure are small. The confidence intervals for their relative risk of death do not exclude the possibility that good rather than harm is being done. This statistical argument may, however, be offset by the consistency of the finding and the plausibility of the possible mechanismcritical reduction of blood flow through narrow coronary arteries in patients with low diastolic blood pressures.

Another possibility is that the benefits of reducing blood pressure may be offset by a harmful effect on other risk factors for coronary heart disease. Thiazide diuretics reduce blood pressure but adversely affect serum lipid concentrations. The
Glasgow group has shown, however, that its J shaped curve was independent of drug treatment, and in some trials thiazides have prevented rather than caused coronary artery disease. ${ }^{112}$ Some trials have specifically excluded patients with coronary heart disease, and they have not shown a J shaped curve. ${ }^{111314}$ In the elderly, among whom undiagnosed narrowing of the coronary arteries might be common, there have been two randomised trials that did not specifically exclude patients with coronary heart disease. One did not find a J shaped curve, ${ }^{15}$ and the other did. ${ }^{16}$ The second study reported a $J$ shaped curve irrespective of whether patients were allocated to drug treatment or to no treatment. ${ }^{17}$ This suggests that the excess deaths are not caused by the drugs.

To sustain his hypothesis that mortality is caused by preexisting heart disease Cruickshank has to disregard the reports from Glasgow and the computing group of a J shaped curve in patients with no previous heart disease. The Glasgow group thinks that its own data give "no direct support" to the idea that harm may be caused by attaining low diastolic pressures; they point out that the relation between achieved diastolic pressure and mortality from stroke is not $\mathrm{J}$ shaped. By contrast the computing group suggest that large falls in diastolic pressure "should be avoided," especially in men with a history of ischaemic heart disease. The two groups have similar results but come to opposite conclusions.

Doctors must be suspicious that they may drop blood pressure too low. Patients whose blood pressures are now "excellent" should be scrutinised carefully for heart disease. Furthermore, there is increasing evidence that when blood pressures are well controlled it may be possible to stop treatment with antihypertensive drugs without blood pressure rising..$^{18}$ Doctors should therefore attempt to reduce or discontinue drug treatment in patients whose pressures have become normal. Patients must be watched closely, and if pressures start to rise again treatment should be restarted. Finally, everybody agrees that patients who have diastolic blood pressures of more than $90 \mathrm{~mm} \mathrm{Hg}$ when they are being treated have a high mortality from coronary heart disease, and steps should thus be taken to improve control.

Reader in Medicine,

D G BEEVERS

Dudley Road Hospital, Birmingham B18 7QH

\footnotetext{
Ledingham JGG, Rajagopalan B. Cerebral complications in the treatment of accelerated hypertension. $Q \mathcal{F}$ Med 1979;48:25-41.

Cove DH, Seddon $M$, Fletcher RG, Dukes DC. Blindness after treatment for undiagnosed hypertension. Br Med $\mathcal{f} 1979 ;$ ii $245-6$.

Anonymous. Dangerous antihypertensive treatment [Editorial]. Br Med $\mathcal{J}$ 1979;ii:228-9.

4 Jackson G, Mahon W, Pierscianowski TA, Condon J. Inappropriate antihypertensive therapy in the elderly. Lancet 1976;ii:1317-9.
} 
5 Anonymous. Hypertension in the elderly [Editorial]. Lancet 1977;i:684-5.

6 Stewart IMcDG. Relation of reduction in pressure to first myocardial infarction in patient treatment for severe hypertension. Lancet 1979; i:861-5.

7 Cruickshank JM, Thorp JM, Zacharias FJ. Benefits and potential harm of lowering high blood pressure. Lancet 1987; ii:581-4.

8 Samuelson $\mathrm{O}$, Wilhelmson L, Anderson OK, Pennert K, Berglund G. Cardiovascular mortality in blood pressure and serum cholesterol levels in treated hypertension. Results from the Primary Prevention Trial in Göteborg. YAMA 1987;258:1768-76.

9 Waller PC, Isles CG, Lever AF, Murray GD, McInnes GT. Does therapeutic reduction in diastolic blood pressure cause death from coronary heart disease? Joumal of Human Hypertension 1988;2:7-10.

10 Fletcher AE, Beevers DG, Bulpitt CJ, et al. The relationship between a low treated blood pressure and IHD mortality: a report from the DHSS Hypertension Care Computing Group (DHCCP). fournal of Human Hypertension 1988;2:11-5.

11 Management Committee. Report. The Australian therapeutic trial in mild hypertension. Lancet $1980 ; \mathrm{i}: 1261-7$.
12 Hypertension Detection and Follow-up Program Collaborative Group. Hypertension Detection and Follow-up Program. I. Reduction in mortality of persons with high blood pressure including and Follow-up Program. 1. Reduction in mort

13 Medical Research Council Working Party. MRC trial of treatment of mild hypertension: principal results. Br Med f 1985;291:97-104.

14 IPPPSH Collaborative Group. Cardiovascular risk and risk factors in a randomised trial of treatment based on the beta blocker oxprenolol. $f$ Hypertens 1985;3:379-92.

15 Amery A, Birkenhäger W, Brixko P, et al. Mortality and morbidity results from the European working party on high blood pressure in the elderly trial. Lancet 1985; i: 1349-59.

16 Coope J, Warrender TS. Randomised trial of treatment of hypertension in elderly patients in primary care. Br Med f 1986;293:1145-51.

7 Coope J, Warrender TS. Lowering blood pressure. Lancet 1987;ii:518.

8 Hundson MF. How often can antihypertensive treatment be discontinued? fournal of Human Hypertension 1988;2:65-9.

19 Fletcher AE, Franks PJ, Bulpitt CJ. The effect of withdrawing antihypertensive therapy: a review. f Hypertens 1988;6:431-6.

\title{
Controlling the carcinoid syndrome
}

\author{
Simple blocking drugs, somatostatin, and then perhaps embolisation
}

Patients with the carcinoid syndrome experience flushing and diarrhoea and sometimes wheezing and progressive right heart failure. The symptoms are caused by the products of carcinoid tumours derived from the foregut or midgut reaching the general circulation. Rarely the syndrome occurs without secondary spread of the tumour (when the venous drainage from a primary carcinoid tumour directly enters the systemic circulation), but most patients have hepatic metastases. Patients with secondary carcinoid deposits survive, however, much longer than patients with secondary adenocarcinoma, and treating the distressing symptoms produced by circulating products from tumours is therefore well worth while. Survival for 15 to 20 years is well recognised, and in some series the mean survival has been as long as eight years from presentation, though three to five years is more usual. ${ }^{1}$ Various approaches to palliating the carcinoid syndrome have been advocated, but there is little agreement on their comparative value.

Conventional radiotherapy to reduce the mass of hepatic tumours is generally agreed to be ineffective at tolerable doses, ${ }^{2}$ though targeting radioactive isotopes with labelled precursors of tumour products is being explored. ${ }^{3}$ Surgical resection is rarely possible as deposits of tumours are generally multiple and in both hepatic lobes. Partial hepatectomy may be considered in roughly one in 10 patients who have the disease predominantly in one lobe. ${ }^{4}$ Alternatively, successful debulking may be achieved by "shelling out" a few large secondaries. ${ }^{5}$ Two problems are that the patients most capable of withstanding a major operation are likely to have a better prognosis than the average and that the release of tumour products during the operation makes it hazardous.

The best results of conventional cytotoxic chemotherapy are currently achieved with combinations of agents, usually including streptozocin. Shrinkage of the tumour or a reduction in circulating tumour products occurs in about a quarter to two fifths of patients, but the price in toxicity deters even enthusiasts. ${ }^{6}$ Human leucocyte interferon given thrice weekly is reported to induce objective responses in about half of the patients ${ }^{7}$ : the disease stabilised or partially remitted for two to three years in the patients who responded. The side effects-predominantly malaise and mild pancytopenia after an initial syndrome like flu had resolved-may be more acceptable than those of conventional chemotherapy.

The dependence of deposits of hepatic tumour on arterial blood flow has initiated three other approaches to debulking tumours. Ligating the hepatic artery at laparotomy tends to be ineffective as the many arterial collaterals rapidly replace the flow from the hepatic artery. Ligating the collaterals as well is a formidable but feasible procedure. ${ }^{8}$ An interventional radiological technique (using multiple emboli through the hepatic artery to obliterate the intrahepatic arterial tree) is a less hazardous option. Many centres have used this procedure since it was first reported in 1977..$^{9}$ Sustained relief of symptoms may be expected for two to 18 months after embolisation, and the procedure may be repeated. ${ }^{10}$ Local symptoms from painful metastases may be relieved. Scrupulous medical care is required before and during the procedure to prevent dangerous circulatory changes after necrosis of the tumour. Embolisation, however, has a mortality of about 3\% and has not been shown to prolong survival. ${ }^{11}$

Rather than reducing the mass of the tumour, the alternative approach is to use drugs to block the synthesis, release, or peripheral actions of the circulating tumour products. Serotonin (5-hydroxytryptamine), the classic mediator, now merely heads a list of potentially active substances that are synthesised and released from carcinoid tumours. The list includes tumour kallikrein, tachykinins, substance $\mathbf{P}$ and other neuropeptides, prostaglandins, and catecholamines. ${ }^{12}$ The varying symptoms of different patients is probably explained by them having differing profiles of active substances, but the relative contribution of these substances to each symptom remains contentious. Treatment with drugs is thus largely empirical.

Recent advances may allow treatment to become less empirical-for example, different classes of serotonin receptor have now been delineated.$^{13}$ Of the drugs that block the 5-hydroxytryptamine type 2 receptor, cyproheptadine often helps the diarrhoea ${ }^{14}$ and ketanserin sometimes but not always helps the flushing. ${ }^{15}$ An antagonist of the 5-hydroxytryptamine type 3 receptor also reduces diarrhoea. ${ }^{16}$ These drugs are generally better tolerated than $p$-chlorphenylalanine, which inhibits synthesis of serotonin, and they may be used with other agents such as antihistamines and non-specific antidiarrhoeal drugs.

A long acting analogue of somatostatin has now emerged as a powerful treatment for the syndrome but is not yet generally available in Britain. Giving the drug thrice daily by subcutaneous injection relieves flushing, diarrhoea, and wheezing in up to four fifths of patients. ${ }^{17}$ The broad effectiveness of somatostatin reflects its multiple actions: it reduces the release of active substances and blocks their peripheral action. Shrinkage of the tumour has even been reported in a few patients. The disadvantages of somatostatin are that progressively larger doses are needed to control symptoms and eventually side effects such as diarrhoea may limit its use. 